\title{
Status of the transition/transfer process for adolescents with chronic diseases at a national pediatric referral hospital in Argentina
}

\author{
Florencia González, M.D., ${ }^{a, b}$ María de las Mercedes Rodríguez Celin, M.D., ${ }^{a}$ \\ Mariana Roizen, M.D. ${ }^{b}$ Roberto Mato, M.D., ${ }^{c}$ Patricia García Arrigoni, M.D., ${ }^{d}$ \\ Florencia Ugo, B.S., ${ }^{e}$ Raquel Staciuk, M.D. ${ }^{b}$ and Virginia Fano, M.D. ${ }^{a}$
}

\begin{abstract}
Introduction: The shift of adolescents from a pediatric to an adult health care facility is a complex process. The objective of this study was to assess the transition/transfer process for adolescents with chronic diseases at Hospital Garrahan.
\end{abstract}

Methods: Observational, cross-sectional, qualitative-quantitative study. Retrospective statistical data were obtained in relation to outpatient visits of patients aged 16-26; surveys and/or interviews were done with health care providers, adolescents, and family members from different follow-up programs.

Results: The prevalence of care provided to individuals older than 16 years was $7.2 \%$. Surveys were administered to 54 attending health care providers, 150 patients (16-26.7 years old) and 141 family members. In addition, 45 health care providers with management functions were interviewed. Health care providers: $39 \%$ had received training on transition. All identified barriers and facilitators among the different participants and facilities. They recognized the importance of encouraging autonomy among their patients, but only $30 \%$ of them interviewed their patients alone, and $56.6 \%$ delivered medical reports. Strategies: the median age of transfer was 18 years (13-20); $62 \%$ had a protocol; $84 \%$ had an informal agreement with another facility; joint or parallel care: $49 \%$; only $20 \%$ implemented a transition plan. Patients and family members: $4.7 \%$ of adolescents attended visits alone, and health care providers had asked $45 \%$ about their autonomy and preparation to take care of their health. Adolescents and their parents had feelings (mostly negative) regarding the process and identified facilitation strategies, such as receiving a summary, knowing the new facility, and having trained health care providers.

Conclusions:Thetransition processforadolescents with chronic diseases is still deficient and approaching it involves health care teams and the families. A lack of formal inter-institutional agreements was identified, although there were more informal agreements among health care providers; besides, the need to encourage chronically-ill patients' autonomy was also determined. In relation to facilitation strategies, patients and parents mainly recognized theneed to have a medical summary, health care guidelines, and trust in the new provider.

Key words: transition to adult care, adolescent, chronic disease, disability, identification of health care needs. http:/ / dx.doi.org/10.5546/ aap.2017.eng.562

To cite: González F, Rodríguez Celin MM, Roizen M et al. Status of the transition/transfer process for adolescents with chronic diseases at a national pediatric referral hospital in Argentina. Arch Argent Pediatr 2017;115(6):562-569.

\section{INTRODUCTION}

Advances in medicine over the last decades have led to increased survival of children with complex pediatric conditions who reach adulthood..$^{1-3}$

The shift of adolescents from a pediatric to an adult health care facility is a complicated process that may cause difficulties for all participating actors and facilities. ${ }^{4-6}$

The actual shift event is called "transfer." Over the last years, a more extensive and complex process has been developed, called "transition," which includes transfer itself. ${ }^{5}$

Such process requires adolescents to acquire skills to increase their autonomy and become more responsible and prepared individuals to face self-care, and for their families and health care teams to be prepared to accompany them. ${ }^{7,8}$

In Argentina, the strategies implemented in practice are still unsystematic and heterogeneous. ${ }^{5}$

Hospital Garrahan is the most important national pediatric referral hospital in Argentina, where children and adolescents with chronic, complex diseases are seen. Although the hospital's rules state that patients older than 18 years cannot continue receiving care here or that no new patients older than 16 years can be admitted to service, given the intricacies of this problem 
in practice, such rules are not followed strictly, and more than $30 \%$ of hospitalized patients are adolescents. ${ }^{9}$

Previous partial assessments showed highly heterogeneous factors in relation to this problem among the different follow-up teams, both in terms of the strategies implemented and the relevance given to transfer. ${ }^{4,9}$

\section{OBJECTIVE}

To assess the transition/transfer process for adolescents with chronic diseases at Hospital Garrahan.

\section{MATERIAL AND METHODS}

Observational, cross-sectional, qualitativequantitative study. Prospective and retrospective data were used.

The study was conducted at Hospital Garrahan in the period between July 2014 and June 2015. Health care providers (HCPs) and patients seen at the hospital, together with their parents, were included.

To determine the prevalence of patients with chronic diseases receiving outpatient follow-up, statistical data were obtained regarding patients aged 16 years and older seen in the year prior to the study (from July $1^{\text {st }}, 2013$ to June $30^{\text {th }}, 2014$ ).

A group of patients with chronic diseases aged 16-26 years, together with their adult caregivers, were included to identify the barriers and facilitators of their transition process. Participants were contacted when they attended a medical checkup at some of the following departments or follow-up programs: Growth \& Development, Gastroenterology (Inflammatory Bowel Diseases and Hepatology), Myelomeningocele, Pulmonology (Asthma, Chronic Obstructive Pulmonary Disease, Cystic Fibrosis of Pancreas, Lung Transplantation), Neurology (Neuromuscular Disease and Epilepsy), Nutrition (Diabetes), Oncology (Solid and Central Nervous System Tumors), Liver and Bone Marrow Transplantation. In addition, these patients also participated in the validation of the TRAQ 5.0 instrument, a questionnaire to assess the preparation of patients for transfer. ${ }^{10}$

HCPs included in the study were part of different outpatient follow-up teams for patients with chronic diseases. Both attending HCPs and those professionals with management functions or responsible for organizing follow-up were contacted to improve knowledge about the different experiences and strategies implemented.
Informed consent was obtained from patients and their parents or families, and an oral consent was requested to HCPs. The study was approved by both the Ethics and the Teaching and Research Committees.

\section{Instruments}

Statistics about care provided to patients aged 16-26 years

Data were provided by the Service of Statistics of the hospital.

\section{Surveys/interviews}

These were developed by consensus of the research team based on the latest advances made on this topic and the knowledge of its status (See Annex 1, 2 and 3).

- Survey for attending HCPs: self-administered questionnaire with 39 close-ended and open questions about opinions, knowledge, practice, and experiences of HCPs in relation to transition/transfer.

- Semi-structured interviews for HCPs with management functions: these were conducted by 2 of the 4 investigators (FG, MR, MRC, FU) at a time and place agreed with the interviewee, and who also made a written account of the interview. Providers were asked about any transfer strategy or protocol and the age for transfer, inter-institutional agreements, the use of a medical summary and / or a referral note, and overlapping of care provided by the two facilities and/or subsequent contact with patients and/or physicians.

- Questionnaire for patients and parents: it included 15 open and close-ended questions for adolescents and 18 questions for their parents. It was about care provided to adolescents and their opinions and expectations about the process.

\section{Definition of outcome measures}

Two new outcome measures were developed, whose definitions were agreed upon based on the bibliography ${ }^{4}$ and the material obtained from the interviews with $\mathrm{HCPs}$ with management functions:

Level of importance given to the transition/transfer process:

- High: a group that shows interest and is already working on this topic.

- Middle: a group that shows interest but is not working on it yet. 
- Low: a group that shows no interest and is not working on it.

Type of transfer:

- Random transfer: there was no consensus by the department or strategies proposed to that end.

- Partially systematic transfer: there was no consensus by the department in terms of age, patient preparation and/or referral facility, but there were informal tools in place used at the moment of transfer.

- Systematic transfer: there was consensus about the referral time and facility but there was no plan for previous preparation.

- Transition: there was a partially consolidated transition plan in place.

\section{Analysis}

To analyze the prevalence of this problem and the answers to the close-ended questions from the surveys administered to patients, families, and HCPs, a descriptive analysis was done using the corresponding summary statistics.

The content of open questions included in the surveys and interviews was analyzed, which included thematic focuses proposed in advance and those developed based on data in a comprehensive and contextual manner. ${ }^{11}$

To analyze the type of transfer and the relevance given to the topic, three investigators (MR, MRC, FG) classified the service independently. If classification was not unanimous, the definition was chosen based on a majority (2 out of 3 ).

\section{RESULTS}

\section{Statistical data}

The group of patients aged 16-26 years accounted for $7.2 \%$ of all outpatient visits (24394 out of 340597 visits in total). Within this group, $31 \%$ corresponded to visits of patients older than 18 years. Visits to the emergency department were excluded.

\section{Health care providers}

Surveys were administered to 54 attending HCPs and 45 HCPs with management functions from contacted health care programs were interviewed among 36 hospital departments. No one refused to participate. Below are the most important findings:

Knowledge about transition (attending HCPs): only $39.6 \%$ referred some basic or postbasic education, and most $(68 \%)$ had read related information on their own.

Health care practices for adolescents with chronic diseases (attending HCPs): as seen in Table 1, most referred practices that somehow encouraged autonomy. However, almost one third never conducted interviews with adolescents alone, and the rate of delivery of complete reports varied.

Barriers and facilitators (attending HCPs, HCPs with management functions): HCPs described barriers among the different process participants (families, patients, physicians, hospitals). They also referred needs and facilitators at the different levels where they observed barriers (Tables 2 and 3 ).

They also suggested that the level of disability, poor treatment adherence, and the lack of places where patients from outside the province of Buenos Aires could be transferred acted as barriers.

Strategies for the transition/transfer process (HCPs with management functions): $62 \%$ had a strategy/protocol available for the transition/transfer process, with the following characteristics.

TABLE 1. Practices implemented in the care of adolescent patients reported by the hospital's health care providers. N: 54

\begin{tabular}{|c|c|c|c|}
\hline & Always & Sometimes & Never \\
\hline Do you ask some of the questions to the patient? & $66 \%$ & $34 \%$ & --- \\
\hline Do you keep parents in the waiting room during part of the visit? & $11.3 \%$ & $58.5 \%$ & $30.2 \%$ \\
\hline Do you consider the level of autonomy of patients to carry out activities of daily living? & $83 \%$ & $15.1 \%$ & $1.9 \%$ \\
\hline Do you introduce the topic of preparing for adult follow-up during the visit? & $65.4 \%$ & $26.9 \%$ & $7.7 \%$ \\
\hline Do you provide education to the patient about his / her disease? & $88.5 \%$ & $11.5 \%$ & --- \\
\hline $\begin{array}{l}\text { Do you provide education to the patient about the names of the medications, dosages, } \\
\text { potential allergies, adverse events or interactions? }\end{array}$ & $62.7 \%$ & $33.3 \%$ & $4 \%$ \\
\hline Do you provide complete medical reports to the patient? & $56.6 \%$ & $39.6 \%$ & $3.8 \%$ \\
\hline Do you encourage the patient to look for or contact an adult care physician? & $57.7 \%$ & $32.7 \%$ & $9.6 \%$ \\
\hline $\begin{array}{l}\text { Do you attempt to identify different barriers in the patient or his / her family for } \\
\text { the transition/transfer process? }\end{array}$ & $50 \%$ & $40.4 \%$ & $9.6 \%$ \\
\hline
\end{tabular}


- Age: $73 \%$ transferred their patients at a specific age. All departments did this as of at least 16 years old, except for one. The median age for referral was 18 years (range: 13-20).

- Agreements: none had a formal agreement with the institutions where patients were referred to; $84 \%$ had an informal agreement, and $16 \%$, none. Subsequent communication and contact with HCPs varied (32\% established further contact; $30 \%$ did not; and 38\%, only sometimes).

- Joint or parallel care: most admitted that an overlapping period is useful for coordinated care between both sites. This practice was somehow implemented by $49 \%$ (joint care, single subsequent visit or overlapping period).

- Type of transfer: $20 \%$ had a transition plan in place; $20 \%$ conducted a systematic transfer; $40 \%$, a partially systematic transfer; and $20 \%$, a random transfer.

- Level of importance given to the issue: high in $40 \%$ of the departments; middle, in $47 \%$; and low, in $13 \%$. Also, $51.9 \%$ were working on this matter.

Other existing strategies (HCPs with management functions): based on the interviews, it was possible to know different, varied experiences already in place and that may serve as models: care provided in a different office specific for adolescents (infectious diseasesHIV, liver transplant, congenital heart disease); monthly education and expression workshops for patients and peers (HIV); multidisciplinary workshops for parents and patients before the transfer (neuromuscular disease team); assessment of preparation for transfer by protocol (nephrology); grand rounds and joint care with adult care physicians (gastroenterologyinflammatory bowel disease, pulmonologycystic fibrosis); training for adult care physicians (metabolic disorders, congenital heart disease). In addition, multiple projects and research fellowships to extend knowledge and experience (nutrition, rheumatology, mental health, social services, hematology and oncology, growth and development, institutional relations, and adolescence) were conducted.

\section{Patients and their families}

A total of 150 patients, with a mean age of 17.5 years (16-26.7) were included; a family member of 141 of them was also included. Only

TABLE 2. Obstacles or barriers reported by surveyed health care providers. N: 54

\begin{tabular}{|c|c|c|c|}
\hline Barriers & Very often & Sometimes & Never \\
\hline \multicolumn{4}{|l|}{ At the facility or health care system } \\
\hline Shift determined exclusively based on the patient's age. & $49 \%$ & $39.2 \%$ & $11.8 \%$ \\
\hline $\begin{array}{l}\text { Lack of communication, interrelations, coordination of actions between pediatric } \\
\text { and adult health care facilities. }\end{array}$ & $61.5 \%$ & $34.6 \%$ & $3.9 \%$ \\
\hline Lack of communication, interrelations, coordination of actions among HCPs & & & \\
\hline $\begin{array}{l}\text { from the children's hospital to agree on transition strategies. } \\
\text { In general, actions are taken in an improvised or random manner, depending }\end{array}$ & $44.2 \%$ & $46.2 \%$ & $9.6 \%$ \\
\hline on each health care provider & $52 \%$ & $44.2 \%$ & $3.8 \%$ \\
\hline \multicolumn{4}{|l|}{ Among pediatricians/pediatric specialists } \\
\hline Overprotection/ paternalism.. & $54.7 \%$ & $39.6 \%$ & $5.7 \%$ \\
\hline Lack of information provided to the patient. & $23.1 \%$ & $51.9 \%$ & $25 \%$ \\
\hline Degradation of adult care physicians. & $30.2 \%$ & $32.1 \%$ & $37.7 \%$ \\
\hline No encouragement of autonomy. & $21.2 \%$ & $53.8 \%$ & $25 \%$ \\
\hline Insufficient information that is necessary for follow-up with adult care providers. & $9.4 \%$ & $52.8 \%$ & $37.8 \%$ \\
\hline \multicolumn{4}{|l|}{ Among adolescent patients } \\
\hline Lack of autonomy. & $33.3 \%$ & $64.7 \%$ & $2 \%$ \\
\hline Severe disease or marked disability. & $40.4 \%$ & $59.6 \%$ & \\
\hline Lack of confidence in the new treating team. & $42.3 \%$ & $53.8 \%$ & $3.9 \%$ \\
\hline Poor treatment adherence. & $24 \%$ & $74 \%$ & $2 \%$ \\
\hline \multicolumn{4}{|l|}{ In the family } \\
\hline $\begin{array}{l}\text { The pediatrician or pediatric specialist is the physician who knows the patient } \\
\text { and his/her family the most. }\end{array}$ & $83 \%$ & $15.1 \%$ & $1.9 \%$ \\
\hline Close bond between the pediatrician and the family. & $88.7 \%$ & $9.4 \%$ & $1.9 \%$ \\
\hline The children's hospital represents a familiar environment. & $88.7 \%$ & $11.3 \%$ & \\
\hline Family resistance against their adolescent child's autonomy. & $47.2 \%$ & $50.9 \%$ & $1.9 \%$ \\
\hline Fear and anxiety regarding the transition process.. & $69.8 \%$ & $30.2 \%$ & --- \\
\hline \multicolumn{4}{|l|}{ Among adult care physicians } \\
\hline Less experience in pediatric chronic diseases. & $60.4 \%$ & $34 \%$ & $5.6 \%$ \\
\hline No habit of introducing the family into health care. & $57.7 \%$ & $40.4 \%$ & $1.9 \%$ \\
\hline
\end{tabular}


2 patients refused to participate. Their opinions are summarized below.

\section{Place given to adolescents during visits}

Only $4.66 \%$ of adolescents referred that they attended visits on their own; the rest went with their parents.

From their perspective, only $45 \%$ had been asked about how they handled anything related to their health, and most $(73 \%)$ considered that these questions were targeted at them and their parents together. In general, questions were related to their overall status, treatment adherence, and personal matters. Very few adolescents and parents indicated that they had been asked about guidelines for autonomy or that they had discussed the characteristics of adult health care facilities $(8.66 \%$ of adolescents and $4.96 \%$ of parents).

However, when faced with the survey's answer options, the two most selected answers were: "They give me more and more explanations so that I understand everything about my health and they talk more directly to me" $(57.5 \%)$ and
"They gave me explanations and a summary of my medical records and the care I need" $(43.2 \%)$. In addition, in relation to communication with their parents, 51\% referred: "They learn everything step by step and it flows naturally."

In relation to parents' opinions, they also perceived that the transition process was still deficient: only less than a half $(41 \%)$ referred that physicians had asked them about their children's preparation to manage their health care on their own and only $51 \%$ indicated that they had been asked about the possibility of making the transfer even though their children were older than 16 years. However, $90 \%$ stated that they had not observed difficulties among HCPs to address adolescents, $15 \%$ indicated that their child had always been taken into consideration during visits, and that children's mean age at process initiation was 12 years (range: 2-16).

\section{Moment for transfer}

Forty-four percent of patients believed they were in the adequate moment to be seen by an adult care physician; the mean reason was that

TABLE 3. Perceived barriers and needs referred by interviewed health care provider

\begin{tabular}{|c|c|}
\hline Barrier/facilitator/need & Perception \\
\hline \multicolumn{2}{|l|}{ Barrier } \\
\hline Lack of communication among HCPs. & $\begin{array}{l}\text { "Many times, the main specialists refer the patient } \\
\text { without informing the rest of the team members." }\end{array}$ \\
\hline Overprotection and paternalism over their patients. & $\begin{array}{l}\text { "Pediatricians are warmer, more perceptive } \\
\text { and fraternal.". }\end{array}$ \\
\hline $\begin{array}{l}\text { The lower level of experience of adult care providers } \\
\text { in the management of pediatric chronic diseases } \\
\text { and the lack of family involvement in care. }\end{array}$ & $\begin{array}{l}\text { "They do not know many of the treatments or } \\
\text { have no experience with them." }\end{array}$ \\
\hline $\begin{array}{l}\text { The close relationship between families and } \\
\text { pediatric care providers. }\end{array}$ & $\begin{array}{l}\text { "These are children that have been receiving follow-up } \\
\text { at the hospital for a long time, so change is difficult } \\
\text { for the families and the specialists." }\end{array}$ \\
\hline \multicolumn{2}{|l|}{ Facilitator } \\
\hline $\begin{array}{l}\text { Development of networks of rotating health care providers } \\
\text { who have received a training scholarship. }\end{array}$ & $\begin{array}{l}\text { "It is useful to have a bond with the rotating health } \\
\text { care providers and the training they receive." }\end{array}$ \\
\hline $\begin{array}{l}\text { An overlapping period between the pediatric } \\
\text { and the adult health care facility. }\end{array}$ & $\begin{array}{l}\text { "This should be a process, so there should be an } \\
\text { intermediate period during which patients } \\
\text { are seen in both settings." }\end{array}$ \\
\hline $\begin{array}{l}\text { Shift to an institutional instance, with formal agreements } \\
\text { in place across the health care system. }\end{array}$ & $\begin{array}{l}\text { "An institutional policy should be in place to foster } \\
\text { communication among directors, with the involvement } \\
\text { of patients, social services, and the health care system." }\end{array}$ \\
\hline $\begin{array}{l}\text { Working with adolescents to prepare them } \\
\text { and encourage their autonomy. }\end{array}$ & $\begin{array}{l}\text { "I had a very unpleasant experience due to lack of preparation: } \\
\text { I had to tell my patients that they could not continue } \\
\text { receiving care here from one day to the next. } \\
\text { I learned from that experience." }\end{array}$ \\
\hline Changes in medical records and summaries delivered. & $\begin{array}{l}\text { "We should introduce a change in the electronic medical } \\
\text { record, such as a warning: patient undergoing transition." } \\
\text { "A summary is not enough; we should provide them } \\
\text { with a guide on the care they need." }\end{array}$ \\
\hline $\begin{array}{l}\text { Warranting that patients will continue to have } \\
\text { a relationship with the pediatric care team. }\end{array}$ & $\begin{array}{l}\text { "We are always in contact, either by e-mail or directly here } \\
\text { in person." }\end{array}$ \\
\hline
\end{tabular}


they felt older and prepared. The reasons referred to indicate that they did not know if they were prepared $(46 \%)$ or that they did not believe they were ready $(10 \%)$ were being used to care received at the hospital, fear of being treated differently, age, and lack of preparation.

Among parents, similarly to their children, $39 \%$ believed that their children were ready for transfer whereas a higher percentage indicated that their children were not prepared $(27 \%$ versus $10 \%)$. The rest did not know. The reasons given by parents in relation to being at the right time for transfer were similar to those given by their children and related to age: "He'll be 20 soon, he feels ashamed around children," "She is an adult now, she is in the university and needs to be surrounded by adults, otherwise she won't grow up."

The reasons why parents did not believe their children were prepared included habit, age, lack of autonomy and trust in the new physician: "We've been coming here for so many years and we've been through many hospital admissions, we feel at home," "He doesn't manage things on his own yet," "I don't see health care providers trained in adolescence and disability."

\section{Feelings associated with the process}

Forty percent of adolescents and $68.6 \%$ of parents had feelings about this process, which were in general negative and, to a lesser extent, positive. Table 4 shows some examples of how patients and parents felt the first time they were approached with the transfer process. Most parents $(74 \%)$ were worried that there would be differences in how their children "would be treated."

\section{Strategies}

In relation to what they considered could help at the time of the transition/transfer, the options that patients chose the most were having a medical summary $(59.9 \%)$ and knowing the new place (54.4\%); however, parents opted for having physicians trained on their child's disease $(70.7 \%)$ and having a medical summary $(70.7 \%)$.

\section{DISCUSSION}

Based on this study, it was possible to make an ample, current diagnosis of the situation about the transition/transfer process conducted in outpatient offices for patients with chronic diseases at Hospital Garrahan. Similarly to the assessment conducted in 2007-2008 in several departments of this and other children's hospitals, a wide variability was observed, from planned transfers to others conducted at random and also in relation to the level of importance assigned to the process. None of the two assessments found formal inter-institutional agreements. A difference was observed in the rate of informal agreements: at present, $84 \%$ of departments have some informal agreement whereas the previous assessment found only $30 \%,{ }^{4}$ which evidences an advancement.

Consistent with previous findings, barriers were found among all involved participants: adolescent patients, families, pediatricians, and adult care physicians and at the level of facilities or systems. These barriers were compared to those analyzed in a consensus by the Argentine Society of Pediatrics, which found similar outcomes. ${ }^{5}$ In addition, such barriers had already been described internationally, regardless of the level of development of countries. A close example is

TABLE 4. Feelings referred by adolescents and their families when faced with the need to be transferred to an adult health care facility

\begin{tabular}{ll}
\hline \multicolumn{1}{c}{ Negative feelings } & \multicolumn{1}{c}{ Positive feelings } \\
\hline $\begin{array}{l}\text { Adolescents } \\
\text { "Fear, I do not know what could happen." . } \\
\text { "It is weird, I did not understand much." } \\
\text { "I have mixed feelings because I do not know }\end{array}$ & "Normal, calm, I knew it would happen some day." \\
how to manage things on my own." & $\begin{array}{l}\text { "Happy, I feel more confident of myself." } \\
\text { "I'm older, more responsible and independent." } \\
\text { "It may work better." }\end{array}$ \\
\hline $\begin{array}{l}\text { Parents } \\
\text { "I feel vulnerable and worried." }\end{array}$ & "It's weird, but necessary; they're older now." \\
"I'm nervous; it means starting all over again." & "I feel safe; we were prepared a long time in advance." \\
"Pediatricians are more involved.". & "I want to know the new place." \\
\hline
\end{tabular}


the document prepared by the Chilean Society of Pediatrics in 2011, which mentioned these barriers and also established that transfer was fixed at 15 years old. ${ }^{6}$

The most relevant strategies recommended by HCPs with management functions were the need of having formal agreements, professional training at the place of origin, network formation, and encouraging autonomy among adolescents. According to families and patients, the process would be easier if they had a medical summary, if the HCP receiving the patient had an adequate training, and knowing the place of referral. These strategies were consistent with bibliographic recommendations, especially regarding the importance of having an updated, accessible medical summary. It has also been suggested to have a written transition plan as of 14 years old, prepared together with the patient and his/her family, which should be updated periodically, and to have guidelines for the assessment and improvement of adolescents' skills. It is important to adapt the preparation according to patients' age range and each patient's situation. ${ }^{12,13,7}$

Another point observed in this study, and consistent with the bibliography, was the need to improve communications between the pediatric and the adult care physicians and to conduct an effective information transfer. ${ }^{6}$

In addition, the difference observed in terms of the "ideal" age for transfer -which parents thought should be older than what their children considered, and which both parents and children considered should be older than what HCPs believed-should also be taken into account given the difficulties observed in relation to change.

Lastly, some of these difficulties will be more easily addressed by the different participants involved but others will require a more overall strategy at an inter-institutional level.

\section{CONCLUSIONS}

The transition process for adolescents with chronic diseases is still deficient and approaching it involves health care teams and the families. A lack of formal inter-institutional agreements was identified, although there were more informal agreements among health care providers; besides, the need to encourage chronically-ill patients' autonomy was also determined. In relation to facilitation strategies, patients and parents mainly recognized the need to have a medical summary, health care guidelines, and trust in the new provider.

\section{Funding}

Florencia González, M.D., received a research grant awarded by the Research Coordination Office and funded by Fundación Garrahan of the Hospital Nacional de Pediatría "Prof. Dr. Juan P. Garrahan" in 2014 ("Development of a transition program for adolescent and young adult patients with chronic diseases in Hospital Garrahan: Laying the foundations") and 2015 ("Expansion of validation and assessment of the usefulness of TRAQ 5.0 tool and spreading of transition challenges at Hospital Garrahan").

\section{REFERENCES}

1. McPherson M, Arango P, Fox H, et al. A new definition of Children with Special Health Care Needs. Pediatrics 1998;102(1 pt 1):137-40.

2. Gortmarker S, Sappenfield W. Chronic childhood disorders: Prevalence and impact. Pediatr Clin North Am 1984:31(3):3-18.

3. NewacheckP,Stoddard J.Prevalence and impact of multiple childhood chronic illnesses. J Pediatr 1994;124(1):40-8.

4. Ugo F, Schejter VH, Carniglia L, et al. La transición del cuidado en el paciente crónico: El largo camino de un hospital pediátrico a un hospital de adultos. Med Infant 2009; 16(1):16-23.

5. GarategarayM,RodriguezPonteM,BreitmanF,etal. Transición deladolescenteconenfermedadescrónicas.Sociedad Argentina de Pediatría, 2011. [Accessed on: July $4^{\text {th }}, 2017$ ]. Available at: http: / / www.sap.org.ar/docs/profesionales/transicion_ del_adolescente_con_enfermedades_cronicas.pdf.

6. Lizama CM, Ávalos AM, Vargas CN, et al. Transición al cuidado de la vida adulta, de niños y adolescentes con necesidades especiales de atención en salud: recomendaciones del Comité NANEAS Sociedad Chilena de Pediatria. Rev Chil Pediatr 2011;82(3):238-44.

7. De Cunto CL. Transición en la atención médica, de la pediatría a la medicina del adulto. Arch Argent Pediatr 2012; 110(4):341-7.

8. Zhang LF, Ho JS, Kennedy SE. A systematic review of the psychometric properties of transition readiness assessment tools in adolescents with chronic disease. BMC Pediatr 2014;14:4.

9. Mato R, Fernández Do Campo, Breyter P, et al. Transición de Adolescentes con Enfermedad Crónica. Resultados de 6 meses de una beca en el Hospital Garrahan enfocada a esta temática. Poster 95 presentado en: Recorrida Poster Digital. $8^{\circ}$ Congreso Argentino de Salud Integral del Adolescente; 15-18 de mayo de 2013; Ciudad Autónoma de Buenos Aires, Argentina.

10. González F, Roizen M, Rodríguez Celin M, et al. Validación español-argentina del cuestionario de transición a la atención médica del adulto en adolescentes con enfermedades crónicas. Arch Argent Pediatr 2017;115(1):18-27.

11. Minayo MCS. El desafío del conocimiento. Investigación cualitativa en salud. Buenos Aires: Lugar; 2004.

12. American Academy of Pediatrics, American Academy of Family Physicians, American College of PhysiciansAmericanSocietyofInternalMedicine.Aconsensusstatement on health care transitions for young adults with special health care needs. Pediatrics 2002;110(6 pt 2):1304-6.

13. American Academy of Pediatrics, American Academy of Family Physicians, American College of Physicians, et al. Supporting the health care transition from adolescence to adulthood in the medical home. Pediatrics 2011;128(1): 182-200. 


\section{ANNEX 1: SURVEY ADMINISTERED TO HEALTH CARE PROVIDERS}

\section{Project: “Development of a transition program for adolescent and young adult patients with chronic diseases at Hospital Garrahan: Laying the foundations" Questionnaire for the health care team}

The advances made in medicine over the last decades have favored the diagnosis, treatment, and management of many pediatric conditions; this has led to an increased survival among many patients who reach adulthood. This depicts a different scenario and need for health care.

This questionnaire has been developed to explore current knowledge and opinions among the HCPs of Hospital Garrahan on this topic and to describe existing strategies in the different departments to transfer patients to the adult health care system in order to lay the foundations for a transition program in our hospital.

To this end, please answer the following questions based on your opinion and to discuss with your team those related to a general position of the department. At the time of returning the survey, please describe the strategies currently in place in more depth.

First and last names:

Date:

Position:

Age:

Department:

Health care program:

\section{Knowledge:}

1. During your training, either basic, post-basic or continuous education (in different settings, fields, etc.), was the topic of transition/transfer discussed?

Yes (1). $\square-$ No (0). $\square$ How?

2. Have you ever read other information to gain more knowledge on this topic?

Yes (1). $\square-$ No (0). $\square$ Do you remember where did you get that information?

\section{Practice:}

3. Do you have a strategy/protocol such as a service for patients' transfer to an adult health care facility? Yes (1). $\square-\mathrm{No}(0)$. $\square$

4. At your department, are patients transferred to an adult care specialist/facility at a given age? Yes (1). $\square-$ No (0). $\square$ Age:

5. Do you know what happens with these adolescents after the transfer?

Yes (1). $\square-$ No (0). $\square$ Sometimes (2). $\square$

Do you keep in touch with patients?

Yes (1). $\square-$ No (0). $\square$ Sometimes (2). $\square$

Do you keep in touch with the new health care providers?

Yes (1). $\square-$ No (0). $\square$ Sometimes (2). $\square$

Providing health care to adolescents with chronic diseases is sometimes a challenge that is hard to manage because our patients are being followed-up since they are very young. Considering your everyday practice, how often do you think the following practices are implemented while providing care to adolescents?

Always (1) Sometimes (2) Never (3)

6. Do you ask some of the questions to the patient?

7. Do you keep parents in the waiting room during part of the visit?

8. Do you consider the level of autonomy of patients to carry out activities of daily living?

9. Do you introduce the topic of preparing for adult follow-up during the visit?

10. Do you provide education to the patient about his/ her disease?

11. Do you provide education to the patient about the names of the medications, dosages, potential allergies, adverse events or interactions?

12. Do you provide complete medical reports to the patient?

13. Do you encourage the patient to look for or contact an adult care physician?

14. Do you attempt to identify different barriers in the patient or his/her family for the transition/transfer process? 


\section{Opinions:}

15. In your opinion, at what age it would be ideal to transfer patients?

16. In addition to age, what other variables do you think should be considered for transfer?

The barriers listed in the following table were presented as potential barriers in a collaborative document by the Argentine Society of Pediatrics (SAP). ${ }^{1}$ When adolescent patients are transferred, and considering your professional experience, please indicate how often you find the following barriers:

At the facility or health care system

17. Shift determined exclusively based on the patient's age.

18. Lack of communication, interrelations, coordination of actions between pediatric and adult health care facilities.

19. Lack of communication, interrelations, coordination of actions among HCPs from the children's hospital to agree on transition strategies.

20. In general, actions are taken in an improvised or random manner, depending on each health care provider.

\section{Among pediatricians/pediatric specialists}

21. Overprotection/paternalism.

22. Lack of information provided to the patient.

23. Degradation of adult care physicians.

24. No encouragement of autonomy.

25. Insufficient information that is necessary for follow-up with adult care providers.

Among adolescent patients

26. Lack of autonomy.

27. Severe disease or marked disability.

28. Lack of confidence in the new treating team.

29. Poor treatment adherence.

\section{In the family}

30. The pediatrician or pediatric specialist is the physician who knows the patient and his/her family the most.

31. Close bond between the pediatrician and the family.

32. The children's hospital represents a familiar environment.

33. Family resistance against their adolescent child's autonomy.

34. Fear and anxiety regarding the transition process.

\section{Among adult care physicians}

35. Less experience in pediatric chronic diseases.

36. No habit of introducing the family into health care.

37. Do you find any other barrier in your everyday practice?

To finish...

38. Is any member of your department currently working on strategies for the transition/transfer process? Yes (1). 口- No (0). $\square$ Who?

39. Would any member of your department be interested in establishing an interdisciplinary team for the transition/transfer process at the hospital?

Yes (1). $\square-$ No (0). $\square$ Who? 


\section{ANNEX 2: SURVEY ADMINISTERED TO PATIENTS}

The following questions will help us to know your opinion, and that of other children in a similar situation, about what we are doing and what we need to change. Answers are personal and anonymous. Please be honest. There are no right or wrong answers. If you have any doubt, please ask us.

1. Do physicians usually ask you how you are preparing to manage your health care on your own? No (0). $\square$ Sometimes (1). $\square$ Almost always (2).

2. Who do physicians ask?

They do not ask (0). $\square$ Me (1). $\square$ My parents (2). $\square$ Both me and my parents (3). $\square$

3. If they ask, what do they ask about?

4. How do you attend the visits with your physicians?

Alone (1). $\square$ With my parents(2). $\square$ With another person (3). $\square$

5. Do you think you are in the adequate moment to be seen by an adult care physician?

No (0). $\square$ Yes (1). $\square$ I do not know (2). $\square$ Why?

6. At what age do you think it would be ideal to be transferred to an adult health care service?

7. How do you imagine the transfer? At what time?

8. Do you have any feelings about the transfer?

No (0). $\square$ Yes (1). $\square$ What?

9. What do you think could help you? (You may select more than one answer).

- Knowing the place (1).

- A place close to my house (2). $\square$

- Having a summary of my medical records (3). $\square$

- To be known when I get transferred there (4). $\square$

- Having physicians specialized in my disease (5).

- Communication with the hospital (6).

10. How do you feel about your physicians' attitudes in relation to you learning about your health?

- They keep talking to my parents; they do not give me an explanation of what happened, is happening or may happen to me (1).

- They explain what is happening step by step, but not what my disease is or what happened to me before (2).

- They give me more and more explanations so that I understand everything about my health and they talk more directly to me (3). $\square$

- They gave me explanations and a summary of my medical records and the care I need (4).

11. How is your relationship with your parents in relation to your health? (You may select more than one answer).

- They are overprotective and do not let me handle things (1). $\square$

- They teach me about my care step by step, but it is hard for them/frightens them (2).

- They teach me everything step by step and it flows naturally (3).

- They leave me alone (4). 
IV / Arch Argent Pediatr 2017;115(6):562-569 / Original article

12. At what age did your parents allow you to start doing something on your own in relation to your health?

Not yet (0). $\square$ Since I was years old.

13. Have you been approached about being transferred to an adult health care facility? No (0). $\square$ Yes (1). $\square$ If you have:

How did you feel when you were first approached with this?

14. Where do you see yourself in 5 years?

15. And in 10 years?

16. Is there anything else you would like to share? 


\section{ANNEX 3: SURVEY ADMINISTERED TO PARENTS}

In addition to knowing your child's opinions about being transferred to adult health care and his/ her readiness, we are interested in knowing his/her parents' or caregivers' opinions on this topic because they have dealt with this for a long time and will accompany him/her in this process. So we would like you to think about your child's care at the hospital so far and to answer the following questions:

1. Do you think your child's chronic disease has implications in the family dynamics?

No (0). $\square$ Yes (1). $\square$ To what extent?

2. Does anyone else in the family have the same disease?

No (0). $\square$ Yes (1). $\square$ Who?

3. How do you feel about your child's health and autonomy? (You may select more than one answer).

- You are overprotective and do not let him/her handle things (1). $\square$

- You teach him/her about his/her care step by step, but it is hard/frightens you (2).

- You teach him/her everything step by step and it flows naturally (3).

- You leave him/her alone (4).

4. Is there a leading physician or a physician that works as primary care physician in the team of health care providers dealing with your child?

No (0). $\square$ Yes (1). $\square$ Who?

5. Considering your relationship with your child's physicians, how would you describe it?

6. It is sometimes common that physicians who see children with chronic diseases since they are young to have problems addressing them directly once they are adolescents to ask them about their perspective of what happens to them.

Do you think this is the case of the health care team treating your child?

No (0). $\square$ Yes (1). $\square$ At what age did they start taking your child into consideration?

7. Do physicians usually ask your child how he/she is preparing to manage his/her health care on his/her own?

No (0). $\square$ Sometimes (1). $\square$ Almost always (2).

Do you think your child is in the adequate moment to be seen by an adult care physician?

No (0). $\square$ Yes (1). $\square$ I do not know (2). $\square$ Why?

8. At what age do you think it would be ideal for your child to be transferred to an adult health care service?

9. How do you imagine the transfer to an adult health care facility?

At what time?

10. Do you have any feelings about the transfer?

No (0). $\square$ Yes (1). $\square$ What?

11. Do you think there will be differences between pediatric and adult health care?

No (0). $\square$ Yes (1). $\square$ What? 
12. What do you think could help at the moment of transfer to an adult health care facility? (You may select more than one answer).

- Knowing the place (1).

- A place close to my house (2).

- Having a summary of my child's medical records (3). $\square$

- For your child to be known when he/ she gets transferred there (4).

- Having physicians specialized in your child's disease (5). $\square$

- Communication with the hospital (6).

13. Have you been approached by the health care team about transferring your child to an adult health care facility?

No (0). $\square$ Yes (1). $\square$

If you have: How did you feel when you were first approached with this?

14. After discussing it, was there any change in the regular dynamics of your child's care? No (0). $\square$ Yes (1). $\square$ What?

15. Have you talked to your child about his/her future? No (0). $\square$ Yes (1).

16. How do imagine your child's life in 5 years?

17. And in 10 years?

18. Is there anything else you would like to share? 